\title{
First breeding record of the light-mantled sooty albatross (Phoebetria palpebrata) for the maritime Antarctic
}

\author{
Simeon Lisovski • Václav Pavel · Karel Weidinger • \\ Hans-Ulrich Peter
}

Received: 28 April 2009 / Revised: 24 July 2009 / Accepted: 27 July 2009 / Published online: 7 August 2009

(C) Springer-Verlag 2009

\begin{abstract}
The light-mantled sooty albatross is a mediumsized albatross with a circumpolar distribution in the Southern Ocean. The known breeding sites are restricted to Islands in sub-Antarctic latitudes close to the Antarctic convergence between $46^{\circ}$ and $53^{\circ} \mathrm{S}$. In the austral summer season 2008/ 2009 we discovered a new breeding colony with at least two confirmed and three probable nests at Fildes Peninsula, King George Island, South Shetland Islands, Antarctica $\left(62^{\circ} 12^{\prime} \mathrm{S}, 59^{\circ} 01^{\prime} \mathrm{W}\right)$. The new breeding colony of lightmantled sooty albatross described here represents the southernmost breeding place of any albatross species ever recorded.
\end{abstract}

Keywords Diomedeidae Phoebetria palpebrata $\cdot$ Fildes Peninsula $\cdot$ Antarctica

The light-mantled sooty albatross (LMSA) (Phoebetrtia palpebrata) is a medium-sized albatross, with grey-brown body and sooty brown head and wings. It has a circumpolar distribution in the Southern Ocean mostly between $40^{\circ}$ and $60^{\circ} \mathrm{S}$ (Brooke 2004). The known breeding sites for LMSA

S. Lisovski $(\bowtie) \cdot$ H.-U. Peter

Polar and Bird Ecology Group, Institute of Ecology,

Friedrich Schiller University Jena,

Dornburger Straße 159, 07743 Jena, Germany

e-mail: Simeon.Lisovski@uni-jena.de

\section{Pavel $\cdot$ K. Weidinger}

Department of Zoology and Laboratory of Ornithology,

Faculty of Science, Palacky University,

Tr. Svobody 26, 77146 Olomouc, Czech Republic are restricted to the sub-Antarctic latitudes, occurring at nine island groups close to the Antarctic convergence between $46^{\circ}$ and $53^{\circ} \mathrm{S}$ (Fig. 1). The largest numbers breed on South Georgia, Kerguelen and Auckland Islands; furthermore, several hundred breeding pairs are recorded on Prince Edward and Marion, Crozet, Heard and McDonald, Macquarie, Campbell and Antipodes Islands (Brooke 2004). Compared with many other albatross species, the LMSA have shown recent increases at two sites, but reliable trend data are unavailable for the majority of the global population: the world population is tentatively estimated at c. 22,000 breeding pairs (Brooke 2004; Crawford et al. 2003; Delord et al. 2008). Despite breeding in the subAntarctic, the LMSAs are the most abundant albatrosses in the Antarctic waters (Ainley et al. 1984) ranging as far south as the border of the Antarctic pack ice in longdistance foraging trips carried out during the breeding season (Lawton et al. 2008; Phillips et al. 2005; Weimerskirch and Robertson 1994).

During the austral summer of 2008/2009 we discovered a new breeding colony with at least two confirmed and three probable nests, located at Fildes Peninsula, King George Island, South Shetland Islands, in the maritime Antarctica $\left(62^{\circ} 12^{\prime} \mathrm{S}, 59^{\circ} 01^{\prime} \mathrm{W}\right)$ (Fig. 1). The breeding site is situated on a steep isolated rock ("Flat Top") in the Drake Passage, about $140 \mathrm{~m}$ high, connected to the island by a $100-\mathrm{m}$-long land bridge. The nests were built on a narrow ledge (1-3 m wide) approximately 15 $20 \mathrm{~m}$ above the sea level, exposed to NNE direction. The rock and the surroundings are sporadically vegetated by algae, lichens and grass (Deschampsia antarctica). Cape petrels (Daption capense) are the only other species breeding on this rock with at least 200 breeding pairs; the minimum distance between nests of the two species was about $30 \mathrm{~m}$. The discovered breeding site is $2.8 \mathrm{~km}$ 


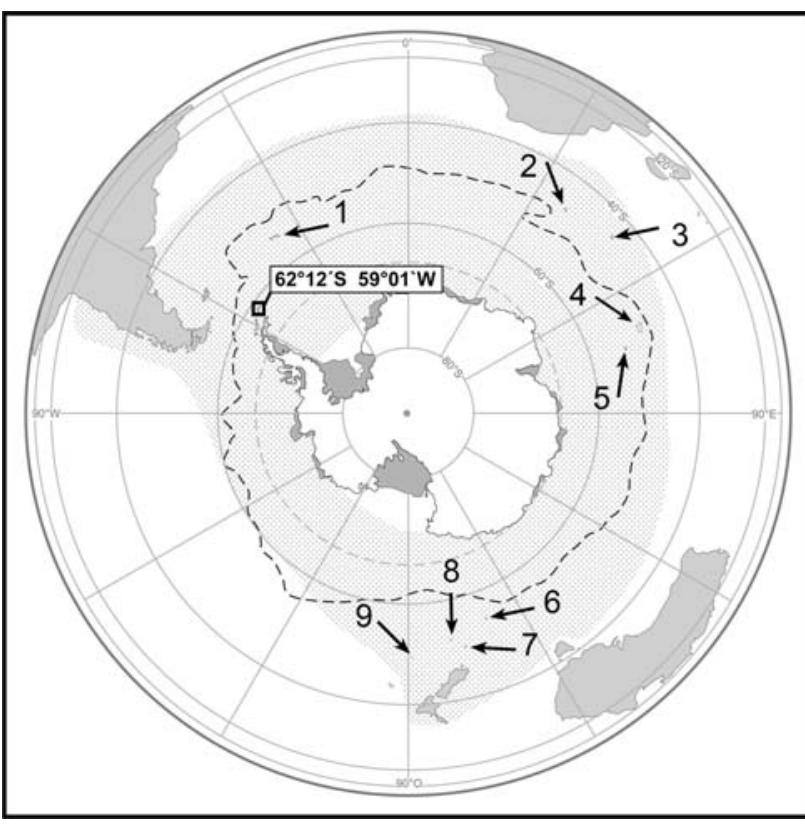

Fig. 1 At-sea (grey) and breeding (arrows) distribution of the lightmantled sooty albatross. Black square indicates new breeding colony at King George Island, South Shetland Islands. (1 South Georgia; 2 Marion Island, Prince Edward Island; 3 Crozet Island; 4 Kerguelen Islands; 5 Heard Island, McDonald Island; 6 Macquarie Island; 7 Auckland Islands; 8 Campbell Islands; 9 Antipodes Islands)

from the nearest human Base (Frei Base, Airfield, Chile).

For the first time on 24 December 2008, in the summer season 2008/2009 we observed adults flying around the cliffs and sitting on the rock ledges. The nest site was then regularly checked every fifth day until the end of February. We usually observe and took pictures from a remote place, because of the inaccessibility of the breeding site. We documented (with pictures) one nest with an egg (with adults sitting nearby) on 25 December 2008 and the same nest and one further nest with nestlings (attended by adults) on 29 February 2009. Given that the age of the nestlings could be estimated as $>20$ days and assuming incubation period of 70 days (Marchant and Higgins 1990), the eggs had to be laid in the middle of November. This is a few days after the range reported from more northerly breeding sites, where the mean laying date is from the end of October to the beginning of November (Marchant and Higgins 1990). During regular observations of this site, we recorded adults sitting frequently at three other places nearby the two confirmed nests with chicks. The observation of five sitting adults, suggesting five active nests, was supported by simultaneous observations of up to four adults flying around the nest site (9 adults in total). However, a large part of the rock is neither accessible, nor visible from the distance so we could not check all potentially suitable nest sites.

The new breeding colony described by us is located about $1,520 \mathrm{~km} \mathrm{SW}$ from the nearest hitherto known breeding place (South Georgia) and represents the southernmost breeding places of any albatross species. Previous observations show that the LMSA have been recorded and may have bred at King George Island even before 2008/2009 (Table 1). Of particular note is the fact that the new breeding site was discovered in one of the most frequently visited parts of the Antarctica (Fildes Peninsula), with seven permanent bases (Council of Managers of National Antarctic Programs 2009) and with a 25-year history of ornithological research (Peter et al. 2008). This demonstrates that even breeding of conspicuous bird species such as the albatrosses may escape attention in well explored areas.

Table 1 Observations of the light-mantled sooty albatross at Fildes Peninsula, King George Island (1984-2008) and the adjacent part of Nelson Island (1990-1992)

\begin{tabular}{lll}
\hline Season & Comment & Reference \\
\hline $1984 / 1985$ & $\begin{array}{l}\text { Multiple censuses of two flying individuals during the season } \\
\text { Two individuals in synchronous flight on 19.11.1984 }\end{array}$ & (Peter et al. 1988) \\
$1987 / 1988$ & One flying individual & (Nadler and Mix 1989, manuscript) \\
$1991 / 1992$ & Three records of one flying individual & (Lumpe and Weidinger 2000) \\
$2004 / 2005$ & Two individuals in synchronous flight and sitting at & (Peter et al. 2008) \\
$2007 / 2008$ & Two individuals flying around the "Flat Top" rock & (H.-U. Peter 2008, personal note) \\
\hline
\end{tabular}

All observations from Fildes Peninsula were made at the coastline near the "Flat Top" 
Acknowledgments We are very grateful to M. Finkelstein and an anonymous referee for providing helpful comments on an earlier draft of the manuscript. S. Lisovski and H.-U. Peter were partially supported by the Deutsche Forschungsgemeinschaft (pe 454/1ff); V. Pavel and $\mathrm{K}$. Weidinger were supported by grants from the Ministry of Education (MSM 6198959212) and Ministry of Environment (VaV SP II 1a9/23/ 07) of the Czech Republic.

\section{References}

Ainley DG, O'Connor EF, Boekelheide JR (1984) The marine ecology of the Ross Sea, Antarctica. Am Ornithol Union Wash Ornithol Monogr 2:1-97

Brooke M (2004) Albatrosses and petrels across the World. Oxford University Press, New York, pp 215-217

Crawford RJM, Cooper J, Dyer BM, Greyling MD, Klages NTW, Ryan PG, Petersen SL, Underhill LG, Upfold L, Wilkinson W, De Villiers MS, Du Plessis S, Du Toit M, Leshoro TM, Makhado AB, Mason MS, Merkle D, Tshingana D, Ward VL, Whittington PA (2003) Populations of surface-nesting seabirds at Marion Island, 1994/95-2002/03. Afr J Mar Sci 25:427-440

Delord K, Besson D, Barbraud C, Weimerskirch H (2008) Population trends in a community of large Procellariiforms of Indian Ocean: potential effects of environment and fisheries interactions. Biol Conserv 141:1840-1856. doi:10.1016/j.biocon.2008.05.001
Lawton K, Kirkwood R, Robertson G, Raymond B (2008) Preferred foraging areas of Heard Island albatrosses during chick raising and implication for the management of incidental mortality in fisheries. Aquat Conserv Mar Freshw Ecosyst 18:309-320. doi: $10.1002 /$ aqc. 857

Lumpe P, Weidinger K (2000) Distribution, numbers and breeding of birds at the northern ice-free areas of the Nelson Island, South Shetland Islands, Antarctica, 1990-1992. Mar Ornithol 28:41-46

Marchant S, Higgins PJ (1990) Handbook of Australian, New Zealand and Antarctic birds, vol 1. Ratites to ducks. Oxford University Press, Melbourne

Peter H-U, Kaiser M, Gebauer A (1988) Untersuchungen an Vögeln und Robben auf King George Island (South Shetland Islands, Antarktis). Geod Geoph Veröff 1:1-127

Peter H-U, Buesser C, Mustafa O, Pfeiffer S (2008) Risk assessment for the Fildes Peninsula and Ardley Island and the development of management plans for designation as Antarctic specially protected or managed areas. UBA-Texte 19:1-353

Phillips RA, Silk JRD, Croxall JP (2005) Foraging and provisioning strategies of the light-mantled sooty albatross at South Georgia: competition and co-existence with sympatric pelagic predators. Mar Ecol Prog Ser 285:259-270

Weimerskirch H, Robertson G (1994) Satellite tracking of light-mantled sooty albatrosses. Polar Biol 14:123-126. doi:10.1007/ BF00234974 